\title{
Structural evolution of an organic/inorganic oxide glass studied by differential scanning calorimetry and mechanical spectroscopy
}

\author{
J. F. CORNU, S. ETIENNE, C. MAI and J. PEREZ
}

Groupe d'Etudes de Métallurgie Physique et de Physique des Matériaux, Institut National des Sciences Appliquées de Lyon, URA CNRS 341, 20 avenue Albert Einstein, 69621 Villeurbanne Cedex, France

\begin{abstract}
Organic/inorganic 3-(trimethoxysilyl)propyl methacrylate/ $\mathrm{SiO}_{2}$ based glass was synthesized by sol-gel process. One objective of the present work was to study the evolution of microstructure and mechanical properties during transformation from hybrid alcogel to hybrid glass.

Results of measurements about physical properties have been obtained by mechanical tests. Microstructural investigation methods such as DSC and Mechanical Spectroscopy were used to get more informations about molecular network behaviour with thermal treatments.

This paper shows that physical properties depend on time because of relaxation effects. These ones have to be measured with a well controlled synthesis chemistry to reach a defined structural state.
\end{abstract}

\section{INTRODUCTION}

New materials such as organic/inorganic glasses are synthesized by sol-gel process. Specific properties can be obtained from these hybrid oxide glasses.

Inorganic oxide glasses are brittle materials below glass transition transition temperature $(\mathrm{Tg})$. It means that they show no region of ductlilty or plasticity, particularly in tensile stress. The brittleness is due to the nature of the chemical bonds. These ones can be modified by introducing organic groups and especially polymeric species in glass composition.

The aim is to obtain a glass exhibiting compromise characteristics of the modulus and the fracture thoughness $\left(\mathrm{K}_{\mathrm{IC}}\right)$ between those of polymers and inorganic oxide glasses.

Those new organic/inorganic oxide glasses are synthesized by sol-gel process [1]. In this study, it will be shown that such a kind of glass can answer those requirements.

\section{EXPERIMENTAL}

\subsection{Materials samples preparation}

The materials and supplier are listed in table 1. All materials were used without further purification.

Table 1

\begin{tabular}{|c|c|c|c|}
\hline Name & Formula & $\mathrm{Mw}$ & Supplier \\
\hline tetraethylorthosilicate (TEOS) & $\mathrm{Si}\left(\mathrm{OC}_{2} \mathrm{H}_{5}\right)_{4}$ & 208.1 & \multirow{5}{*}{ Aldrich } \\
\hline tetramethylorthosilicate (TMOS) & $\mathrm{Si}_{\left(\mathrm{OCH}_{3}\right)_{4}}$ & 152.2 & \\
\hline $\begin{array}{l}\text { 3-(trimethoxysilyl)propyl } \\
\text { methacrylate }\end{array}$ & $\mathrm{H}_{2} \mathrm{C}=\mathrm{C}\left(\mathrm{CH}_{3}\right) \mathrm{CO}_{2} \mathrm{C}_{3} \mathrm{H}_{6} \mathrm{Si}\left(\mathrm{OCH}_{3}\right)_{3}$ & 248.3 & \\
\hline methylmethacrylate (MMA) & $\mathrm{H}_{2} \mathrm{C}=\mathrm{C}\left(\mathrm{CH}_{3}\right) \mathrm{COO}-\mathrm{CH}_{3}$ & 100.1 & \\
\hline benzoyl peroxide & $\left(\mathrm{C}_{6} \mathrm{H}_{5} \mathrm{CO}\right)_{2} \mathrm{O}_{2}$ & 242.2 & \\
\hline
\end{tabular}


At first, TEOS (or TMOS) were mixed with 3-(trimethoxysilyl)propyl methacrylate. Then an appropriate amount of distilled water and hydrochloric acid (in case of acidic catalysis) were added.Separately a solution of monomer: methyl methacrylate and benzoyl peroxide as catalyst had been prepared. The two mixtures were blended and at last, the suitable solvents were added. This sol was poured into a Teflon Petri disk and stirred for 4 hours at $50^{\circ} \mathrm{C}$. Then it was covered with a protective film (not tightly to permit evaporation of the solvents) and let at $50^{\circ} \mathrm{C}$ for 48 hours. The solution formed a leatherlike transparent gel after this delay.

\subsection{Evolution of microstructure}

Microstructural evolution has been studied for the two stages of the synthesis of an organic/inorganic oxide glass.

At first; by Infra-Red, Raman [2] and NMR spectroscopies [3] during the gelation and polymerization process.

In a second step, investigations have been made about the process which leads from hybrid oxide alcogel to hybrid oxide glass by thermal treatments. Mainly, Differential Scanning Calorimetry (DSC) and Mechanical Spectroscopy techniques were employed.

\subsection{Mechanical tests}

Microhardnesses $\left(\mathrm{H}_{\mathrm{V}}\right)$ were measured [1] by Vickers Indentation techniques. Measurements for other elastic constants as Young modulus (E), bulk modulus (B), shear modulus (G) and Poisson coefficient ( $v$ ) by ultra sonic waves are in progress [4].

\section{RESULTS AND DISCUSSION}

\subsection{Microstructural characterization}

According to Schmidt and coworkers [5], a possible chemical reaction is:

starting components

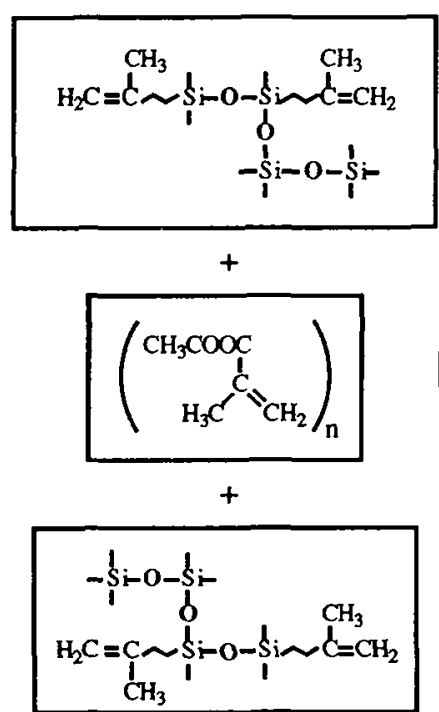

resulting organic/inorganic network

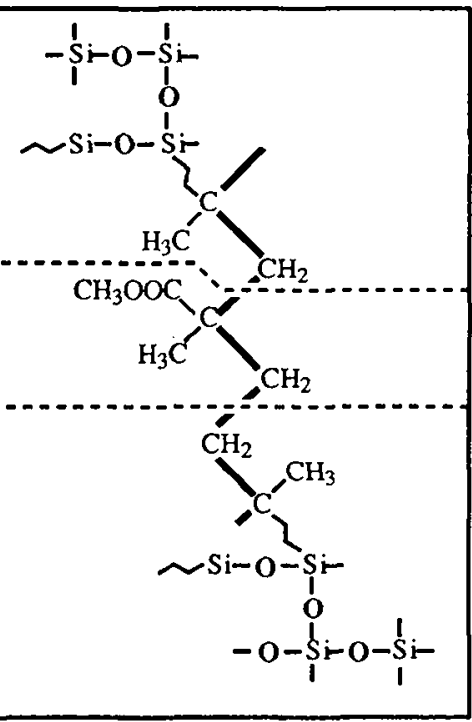

Infra-Red, Raman and NMR spectroscopies display a few reactional mechanisms which are important to know because they determine final geometry of molecular network in this kind of material. Indeed, we have to consider that during the process there is a competition between two phenomena: 
1/ gelation: for silica alkoxide (TMOS or TEOS)/ $\mathrm{H}_{2} \mathrm{O}$ and 3-(trimethoxysilyl)propyl methacrylate (MTAS) $/ \mathrm{H}_{2} \mathrm{O}$ (hydrolysis \& condensation), which leads to the silica network.

2/ radicalar polymerization: which leads from methylmethacrylate (MMA) to polymethylmethacrylate (PMMA).

It has been confirmed by Mechanical Spectroscopy (see 3.2.2.) that in acidic catalysis, gelation occurs faster than radicalar polymerization. The main consequence is that there are MMA oligomers existing isolated in slits of the molecular network. There are PMMA short polymeric chains too, linked with the silica network.

A prospect is to get a tridimensionnal idea of the network formation because it seems to be the only way to understand some molecular behaviours.

\subsection{Evolution of microstructure}

\subsubsection{From hyrid alcogel to hybrid glass}

When the material sample has just been synthesized (see 2.1.), it looks like a transparent solid with a liquid film on its surface. At this time, the jelly-like consistency of the material indicates that solvent is still present. It is necessary to cause desorption and densification by a specific thermal treatment. DSC curves (see Fig.1) show an endothermal desorption peak located about $353 \mathrm{~K}$ whose amplitude decreases with extension of treatment time. It disappears completely if the material is cured for a sufficient duration (it can be noticed that this time depends on sample geometry).

The DSC curves show also an exothermal peak about f Heat Flow Exothermal (mW)

$423 \mathrm{~K}$ attributed to the end of crosslinking in the material. 10000

This one disappears with thermal treatment (see Fig. 3).

Figure 1: DSC curves obtained for the same kind of sample (weight: $20 \mathrm{mg}$; heating rate: $10 \mathrm{~K} / \mathrm{mn}$ ) for 3 successive treatments at $353 \mathrm{~K}$.

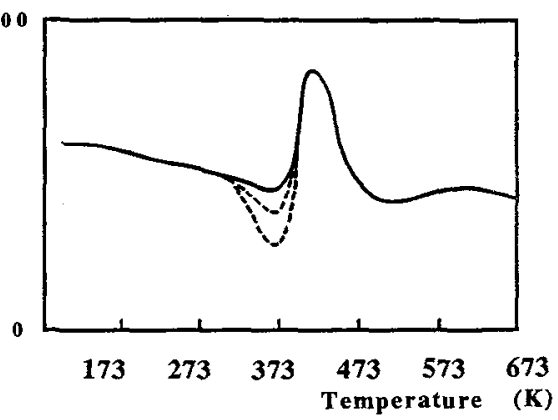

\subsubsection{Evolution of molecular network with thermal treatments}

Correlating DSC and Mechanical Spectroscopy allows to get new data about organic/inorganic oxide glasses. Measurements (see Fig.2 \& 3) have been done on samples cured first at $353 \mathrm{~K}$ (solvents eliminated). For each one, we made series of successive heatings:

1/ from $97 \mathrm{~K}$ to $373 \mathrm{~K} ; 2$ / from $97 \mathrm{~K}$ to $413 \mathrm{~K} ; 3$ / from $97 \mathrm{~K}$ to $443 \mathrm{~K} ; 4$ / from $97 \mathrm{~K}$ to $473 \mathrm{~K}$

The objective is to observe microstructural behaviour, mainly around $423 \mathrm{~K}$.

On Figure 2, Phi is the phase lag (loss angle of the complex shear modulus or dynamic modulus $\mathrm{G}^{*}$ ) such as $G^{*}(\omega)=G^{\prime}(\omega)+j G^{\prime \prime}(\omega)=$ G.e ${ }^{j P h i}$. Isochronal curves (Tan Phi) highlight three appearent relaxation processes (convolution of three peaks) related with molecular reorderings or movements.

At low temperature $(133 \mathrm{~K})$ there is a weak relaxation phenomenon (attributed to water) which manifests as a shoulder on the spectrum. At higher temperatures ( $200 \mathrm{~K}$ and $283 \mathrm{~K})$, two other relaxation phenomena occur.

The spectra were carried out at different frequencies $(1 \mathrm{~Hz}, 0.3 \mathrm{~Hz}$ and $0.09 \mathrm{~Hz})$. To be clearer, only $v=1 \mathrm{~Hz}$ is represented on Figure 2. Then, appearent activation energies (Ea) and attempt frequencies ( $\mathrm{vo}_{\mathrm{o}}$ have been calculated for the two last peaks.

At $\mathrm{T}=200 \mathrm{~K} ; \mathrm{Ea}=0.56 \mathrm{eV} ; v_{0}=10^{14} \mathrm{~Hz}$. It means that there is a non-cooperative (Arrhenian) process: there are local molecular movements. The phenomenon corresponds to a $\beta$ relaxation and is quasiindependant on thermal treatments. 
At $\mathrm{T}=283 \mathrm{~K} ; \mathrm{Ea}=1.3 \mathrm{eV} ; \mathrm{v}_{0}=10^{24} \mathrm{~Hz}$. Higher Ea associated with a very high frequency factor suggests we have a primary or so called $\alpha$ relaxation. The process is cooperative and dependant on time. It could correspond to glass transitions of oligomers.

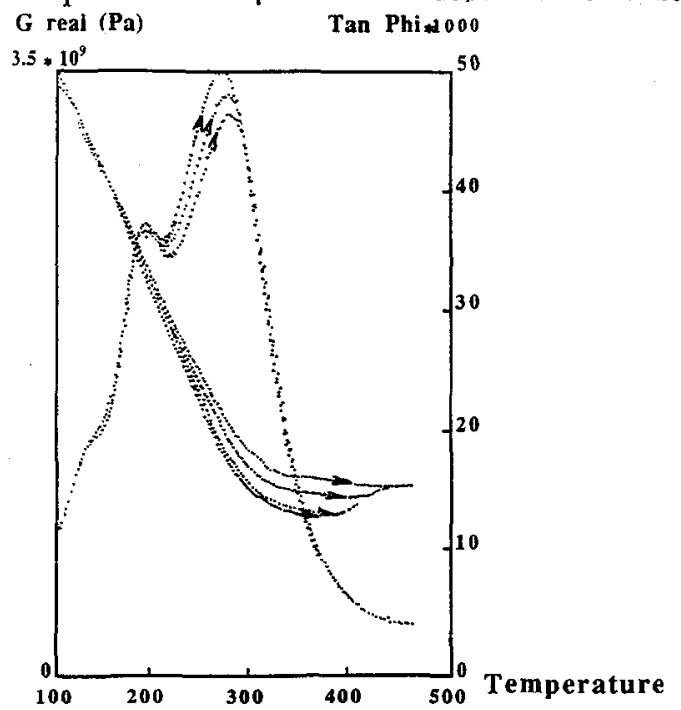

Figure 2: Mechanical Spectroscopy for an organic/inorganic oxide glass. Heating rate: $1 \mathrm{~K} / \mathrm{mn}$. $v=1 \mathrm{~Hz}$.

During successive heatings, it is noticed that from $433 \mathrm{~K}$, storage modulus ( $\mathrm{G}$ real) goes up: in the network, new links may appear: short oligomers crosslink or lengthen. Mechanical Spectroscopy can be correlated with DSC measurements (see Fig.1 also) which have been done in the same temperature areas.

Heat Flow Exothermal (mW)

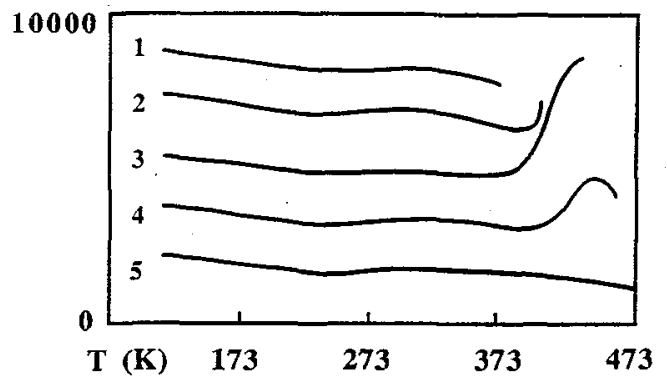

Figure 3: DSC curves have been shifted to have more clearness:

1/ up to $373 \mathrm{~K}$ : no change

2/ up to $413 \mathrm{~K}$ : beginning of crosslinking

3/ up to $433 \mathrm{~K}$ : continuation of crosslinking

4/ up to $453 \mathrm{~K}$ : end of crosslinking

$5 /$ up to $473 \mathrm{~K}$ : the peak disappears

\section{CONCLUSION AND PROSPECTS}

Organic/inorganic oxide glasses are based on the incorporation of organic functionalized polymers into an inorganic glass by the sol-gel process. New physical properties have been observed and especially an evolution of microstructure during thermal treatments. Other studies [1-4] have shown that synthesis chemistry determines strongly the behaviour of the future material.

For instance, a prospect is to modify the microstructure while changing catalysis $\mathrm{pH}$ or silica contents with the aim to establish a correlation between microstructural and macromechanical properties.

\section{REFERENCES}

[1] MAI, C; CORNU, J.F; BOURAS, S; VASSOILLE, R and PEREZ, J, Eurogel 91, Saarbrücken.

[2] BUREAU, J.C; BAKKALI, A; CORNU, J.F and MAI, C (to be published).

[3] BABONNEAU, F; CORNU, J.F and MAI, C (to be published).

[4] CORNU, J.F and ETIENNE, $S$ (to be published).

[5] SCHMIDT, H and PHILIPP, G, J. of Non Cryst. Solids, 63 (1984) 283-292. 